\title{
Flexible Gas Sensor Printed on a Polymer Substrate for Sub-ppm Acetone Detection
}

\author{
W. Andrysiewicz ${ }^{1} \cdot$ J. Krzeminski ${ }^{2} \cdot K_{\text {. Skarżynski }} \cdot$ K. Marszalek $^{1} \cdot$ M. Sloma ${ }^{2} \cdot$ A. Rydosz ${ }^{1}$ D
}

Received: 8 November 2019 / Accepted: 7 January 2020 / Published online: 20 January 2020

(c) The Author(s) 2020

\section{Abstract}

Gas sensors are widely used in many industrial and home applications. There is therefore continued need to develop novel gas sensor substrates which provide good mechanical and electrical stability, and good flexibility in comparison with the conventional alumina and silicon-based materials. In this paper, we present the experimental results on flexible gas sensors based on the Kapton foil and alumina substrate covered by copper oxide as a gas-sensitive layer. These sensors exhibited good mechanical stability and gas-sensing characteristics. The Kapton-based $\mathrm{CuO}$ gas sensors were tested under exposure to acetone in the $0.05-1.25 \mathrm{ppm}$ range $\left(150^{\circ} \mathrm{C}, 50 \% \mathrm{RH}\right)$. The results confirmed that sensors deposited on the flexible substrate such as Kapton can be used in the exhaled breath analyzers dedicated to diabetes biomarker detection or other applications for which the elastic substrate is needed.

\section{Graphic Abstract}

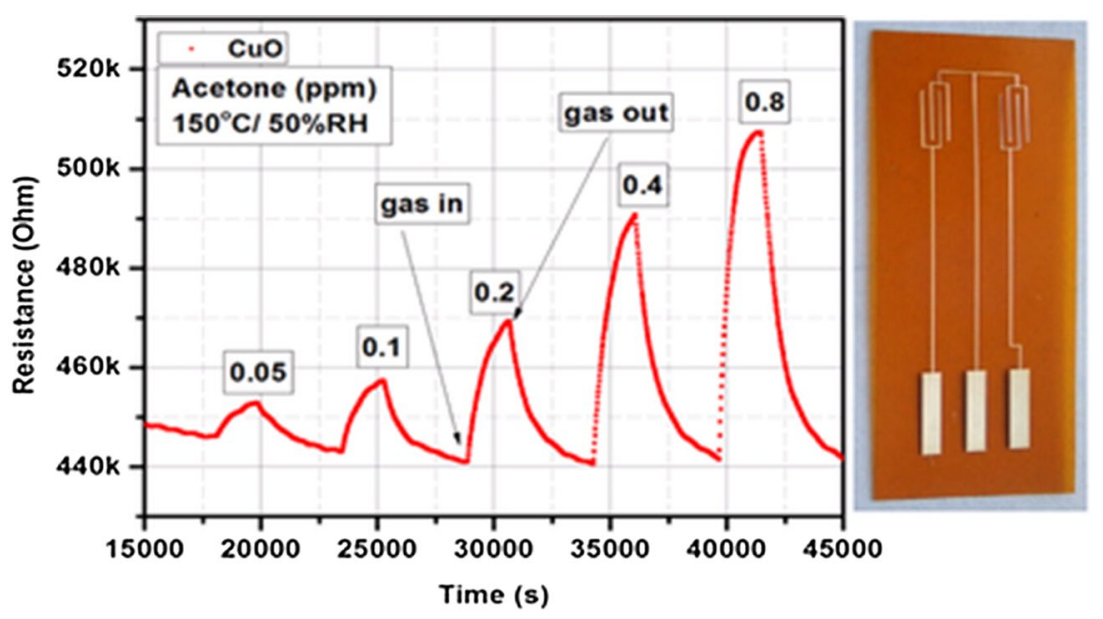

Keywords Gas sensors · Elastic gas sensor substrates · Acetone detector

A. Rydosz

artur.rydosz@agh.edu.pl

W. Andrysiewicz

wojciech.andrysiewicz@agh.edu.pl

J. Krzeminski

krzem@mchtr.pw.edu.pl

K. Skarżynski

skarzynskikacper@gmail.com

K. Marszalek

konstanty.marszalek@agh.edu.pl

\section{Sloma}

marcin.sloma@pw.edu.pl

1 Department of Electronics, AGH University of Science and Technology, Al. Mickiewicza 30, Kraków, Poland

2 Micro- and Nanotechnology Division, Institute of Metrology and Biomedical Engineering, Faculty of Mechatronics, Warsaw University of Technology, 8 sw. A. Boboli st, 02-525 Warsaw, Poland 
Abbreviations

$\begin{array}{ll}\text { ABS } & \text { Acrylonitrile butadiene styrene } \\ \text { CNF } & \text { Carbon nanofibers } \\ \text { FDM } & \text { Fused deposition modelling } \\ \text { GO } & \text { Graphene oxide } \\ \text { ITO } & \text { Indium-tin oxide } \\ \text { NF } & \text { Nanofibers } \\ \text { NMF } & \text { Nanofibrous mesh } \\ \text { NP } & \text { Nanoparticles } \\ \text { NR } & \text { Nanorods } \\ \text { NS } & \text { Nanostructures } \\ \text { NSph } & \text { Nanospheres } \\ \text { PANI } & \text { Polyaniline } \\ \text { PC } & \text { Colycarbonate } \\ \text { PET } & \text { Eolyethylene terephthalate } \\ \text { PI } & \text { Polyimide, trademarked as Kapton } \\ \text { PPy/N-MWCNT } & \text { Polypyrrole/nitrogen-doped multiwall } \\ & \text { carbon nanotube } \\ \text { PTFE } & \text { Polytetrafluoroethylene }\end{array}$

$\begin{array}{ll}\text { rGO } & \text { Reduced graphene oxide } \\ \text { RH } & \text { Relative humidity } \\ \text { RT } & \text { Room temperature } \\ \text { SWCNT } & \text { Single-walled carbon nanotubes }\end{array}$

\section{Introduction}

Gas detectors have been developed over the few last decades in response to industrial demands: for the monitoring of air quality [1], in the automotive industry [2], in medicine for the detection of biomarkers in various diseases [3-5]. In principle, a gas sensor consists of a gas sensor substrate with a gas-sensitive layer, and package. Gas sensor substrates are usually realized in alumina [6], LTCC (low temperature cofired ceramics) [7-9] and silicon technology [10], and gas-sensitive layers are based on metal oxides [11-14]. Flexible gas sensor substrates are very promising in the portable exhaled breath analyzers. In recent years,

Table 1 A summary of the recently reported research on gas-sensing applications with flexible gas sensor substrates

\begin{tabular}{|c|c|c|c|c|c|c|}
\hline $\begin{array}{l}\text { Flexible substrate } \\
\text { material }\end{array}$ & Gas-sensing layer material & Target gas & $\begin{array}{l}\text { Concentration } \\
(\mathrm{ppm})\end{array}$ & Response & $\begin{array}{l}\text { Operating } \\
\text { temp. }\left({ }^{\circ} \mathrm{C}\right)\end{array}$ & References \\
\hline PET & Polyaniline & $\mathrm{NH}_{3}$ & 25 & $4.29 * *$ & RT & [17] \\
\hline PET & $\mathrm{TiO}_{2}+\mathrm{Bi}_{2} \mathrm{WO}_{6}(\mathrm{NF})$ & Ethanol & $\begin{array}{l}50 \\
800\end{array}$ & $\begin{array}{l}12.6 \% * * \\
60 \% * *\end{array}$ & RT & {$[20]$} \\
\hline PET & $\begin{array}{l}\mathrm{Cu}- \\
-\left(\mathrm{CH}_{3} \mathrm{COO}\right)_{2}\end{array}$ & $\mathrm{H}_{2} \mathrm{~S}$ & 10 & $10^{\wedge} 5^{*}$ & RT & [19] \\
\hline PET & $\mathrm{SWCNT}+\mathrm{Cu}$ & $\mathrm{H}_{2} \mathrm{~S}$ & 20 & $25 \% * *$ & RT & {$[24]$} \\
\hline PET & $\mathrm{In}_{2} \mathrm{O}_{3}(\mathrm{NSph})+\mathrm{Au}$ & $\mathrm{NH}_{3}$ & 100 & $46^{*}$ & RT & {$[25]$} \\
\hline PET & Polyaniline- $\mathrm{WO}_{3}$ & $\mathrm{NH}_{3}$ & 100 & $121 \% * *$ & RT & {$[26]$} \\
\hline PET & $\mathrm{SnO}_{2} / \mathrm{rGO} / \mathrm{PANI}$ & $\mathrm{H}_{2} \mathrm{~S}$ & 0.2 & $23.9 \% * *$ & RT & {$[27]$} \\
\hline PET & Polyaniline hydrohloride & $\mathrm{NH}_{3}$ & 50 & $2.1^{*}$ & RT & {$[28]$} \\
\hline PI/PTFE & $\mathrm{ZnO}(\mathrm{NR})+\mathrm{Ag}$ polyaniline coated & $\mathrm{C}_{2} \mathrm{H}_{2}$ & 1000 & $27.2 *$ & 200 & [29] \\
\hline PI & $\mathrm{WO}_{3}(\mathrm{NS})+\mathrm{Au} / \mathrm{Pt}$ & $\begin{array}{l}\text { Methanol } \\
\text { Ethanol } \\
\text { Acetone } \\
\text { Toluene }\end{array}$ & 2000 & $\begin{array}{l}4.3^{*} \\
6.4^{*} \\
2.0^{*} \\
1.8^{*}\end{array}$ & $150-250$ & [16] \\
\hline PI & $\mathrm{Zn}_{2} \mathrm{GeO}_{4}$ & $\mathrm{NH}_{3}$ & 200 & $831 * *$ & RT & {$[30]$} \\
\hline PI & $\left.\mathrm{TiO}_{2-\mathrm{x}}\right)$ & $\mathrm{NH}_{3}$ & 100 & $7 \% * *$ & 210 & {$[31]$} \\
\hline PI & $\mathrm{WO}_{3}$ & Ethanol & 100 & $3 \% * *$ & 220 & {$[32]$} \\
\hline PI & $\mathrm{CNF}+\mathrm{Au} / \mathrm{Pd}$ & $\mathrm{NH}_{3}$ & 500 & $3 \% * *$ & 120 & {$[33]$} \\
\hline PI & Polyaniline- $\mathrm{CeO}_{2}$ & $\mathrm{NH}_{3}$ & 10 & $106.9 \% * *$ & RT & {$[34]$} \\
\hline PI & PPy/N-MWCNT) & $\mathrm{NO}_{2}$ & 5 & $24.82 \% * *$ & RT & {$[35]$} \\
\hline PI & $\mathrm{TiO}_{2}$ & Trimethylamine & 100 & $1.7^{*}$ & RT & {$[36]$} \\
\hline PI & $\mathrm{ZnO}(\mathrm{NP})$ & $\begin{array}{l}\mathrm{NH}_{3} \\
\mathrm{O}_{3}\end{array}$ & $\begin{array}{l}0.1 \\
0.2\end{array}$ & $\begin{array}{l}1.32^{*} \\
15^{*}\end{array}$ & $\begin{array}{l}300 \\
200\end{array}$ & {$[37]$} \\
\hline ITO-PET & GO & Isoprene & $25 \mathrm{ppm}$ & $0.7 \% * *$ & RT & {$[38]$} \\
\hline Nylon fabric & rGO-NFM & $\mathrm{NO}_{2}$ & 1 & $13 \% * *$ & RT & [39] \\
\hline $\mathrm{PC}$ & $\mathrm{Cu} / \mathrm{Cu}_{\mathrm{x}} \mathrm{O}$ & $\mathrm{RH}$ & $0-95 \%$ & $60 \% * *$ & RT & {$[21]$} \\
\hline
\end{tabular}

$* \mathrm{R}_{\mathrm{a}} / \mathrm{R}_{\mathrm{g}}$ or $\mathrm{R}_{\mathrm{g}} / \mathrm{R}_{\mathrm{a}}$

$* *\left(\mathrm{R}_{\mathrm{g}-} \mathrm{R}_{\mathrm{a}}\right) / \mathrm{R}_{\mathrm{a}}$, where $\mathrm{Ra}$ and $\mathrm{Rg}$ are electrical resistances in air and target gas, respectively 
flexible gas sensors have become increasingly attractive due to a number of advantages such as miniaturization, and portable or wearable properties. Flexible gas sensors based on the plastic substrates (plastic polyimide, PI) with titania nanotube (TNT) gas-sensitive layer for carbon monoxide (CO) and ammonia $\left(\mathrm{NH}_{3}\right)$ detection were reported in 2014 by Jang et al. [15]. The authors described gas-sensing performance of the flexible TNT sensors in which electrical current was measured during exposure to $\mathrm{CO}$ and $\mathrm{NH}_{3}$ at $350{ }^{\circ} \mathrm{C}$ working temperature. The gas sensor response was defined as $\left(\mathrm{I}_{\text {gas }}-\mathrm{I}_{0}\right) / \mathrm{I}_{0} \times 100(\%)$, where $\mathrm{I}_{\text {gas }}$ and $\mathrm{I}_{0}$ are the electrical currents measured at exposure to target gas and air, respectively. Both gases were used in the 0-200 ppm concentration range, and the response obtained by the authors was $68.3 \%$ and $77.9 \%$ for $200 \mathrm{ppm}$ of $\mathrm{CO}$ and $\mathrm{NH}_{3}$ gases, respectively [15]. The main limitation of those sensors is still a high working temperature of $350{ }^{\circ} \mathrm{C}$. The detection of volatile organic compounds (VOCs) using flexible gas sensing devices was reported in 2015 by Vallejos et al. [16]. The gas sensors were based on highly crystalline tungsten oxide nanostructures functionalized with $\mathrm{Au}$ and $\mathrm{Pt}$ nanoparticles. These sensors were fabricated using commercial high heat resistant polyimide, where interdigital electrodes and heater were deposited. Gas-sensing tests were conducted at various operating temperatures (from 150 to $250{ }^{\circ} \mathrm{C}$ ) and $0.2 \%$ concentrations of VOCs, such as ethanol, methanol, acetone, and toluene. The highest responses $\left(\mathrm{R}_{\mathrm{a}} / \mathrm{R}_{\mathrm{g}}\right.$, where $\mathrm{R}_{\mathrm{a}}$ and

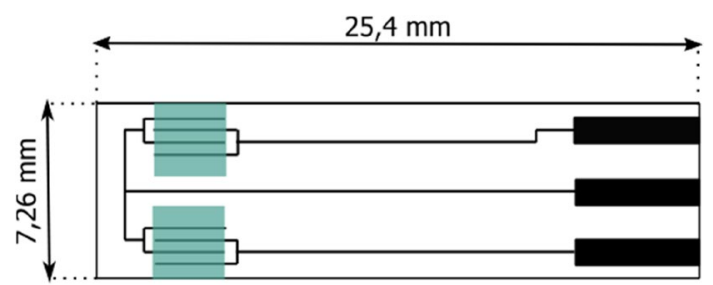

Fig. 1 The comb-shaped electrode designed for the sensor. Three contact pads, $1 \times 5 \mathrm{~mm}$ with $2.54 \mathrm{~mm}$ pitch, are used to connect external measuring systems. Each electrode has two measuring areas
$\mathrm{R}_{\mathrm{g}}$ are electrical resistances to air and target gas, respectively) were obtained for $\mathrm{Pt}: \mathrm{WO}_{3}$ to methanol and $\mathrm{Au}: \mathrm{WO}_{3}$ to acetone at $220^{\circ} \mathrm{C}$ [16]. A limitation of those sensors is the detection of high VOCs concentrations (2000 ppm). Apart from plastics and polyimide substrates, poly-PET (ethylene terephthalate) substrates were used for ammonia detection; the result for this material were reported in 2017 by Kumar et al. [17]. The authors presented gas sensors based on polyaniline (PANI) films as an active sensing layer. The PANI films were successfully deposited on a polyethylene terephthalate (PET) flexible substrate by a simple in situ polymerization technique. Ammonia gas-sensing properties of the films prepared at optimum conditions were examined at room temperature in the range of 5-1000 ppm. The fabricated sensors exhibited high responses and good longterm stability [17]. Similar results were reported by Hua et al. [18]. The single-walled carbon nanotubes (SWNTs)$\mathrm{Fe}_{2} \mathrm{O}$ composite films deposited on plastic substrates were investigated as a potential gas sensor for $\mathrm{NH}_{3}, \mathrm{NO}$ and $\mathrm{NO}_{2}$ detection [18]. Recently, various different gas-sensing applications have been reported, including $\mathrm{H}_{2} \mathrm{~S}$ detection with inkjet-printed copper acetate on a flexible plastic substrate [19], ethanol detection with sensor consisting of a $1 \mathrm{D} \mathrm{TiO}{ }_{2}$ nanofiber wrapped in a shell of $\mathrm{Bi}_{2} \mathrm{WO}_{6}$ nanosheets [20], and humidity detection of $\mathrm{Cu} / \mathrm{Cu}_{\mathrm{x}} \mathrm{O}$ integrated structure on flexible polycarbonate substrates [21]. Table 1 shows a brief summary of these recent studies, and a thorough review of flexible gas sensors can be found in Alrammouz et al. [22]. These authors conclude that flexible gas sensors are still in the development stage, and that future work will hopefully include new fabrication techniques, along with new composite materials and substrates, and that the field moves toward the integration of gas sensors in e-textiles, smart-packaging and application of sensors in the unconventional places [22].

In this paper, we describe a deposition of a copper oxidebased acetone sensor on a polymer substrate, with aim to enhance acetone detection and to bring the limit of detection of acetone into the sub-ppm range. These sensors are the main element of the portable exhaled breath analyzer for

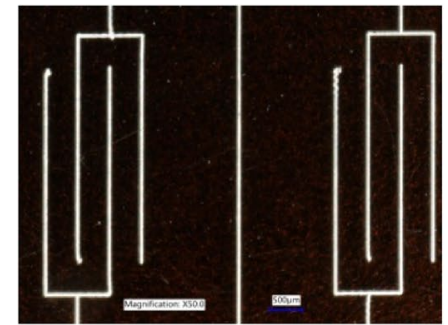

(a)

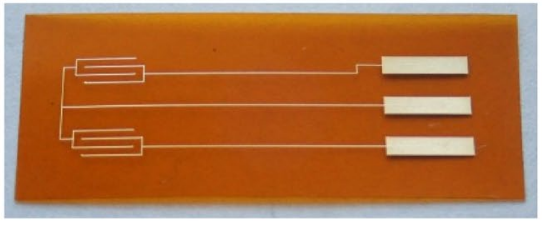

(b)

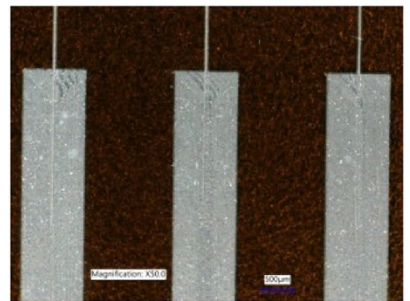

(c)

Fig. 2 Micrographs of the printed sensor electrodes and contact pads; a zoom to head area with magnification $\times 50.0$, $\mathbf{b}$ general view of the electrode layer; $\mathbf{c}$ zoom to contact pad with magnification $\times 50.0$ 
noninvasive diabetes monitoring, which is currently patent pending in the European Patent Office [23].

\section{Materials and Methods}

\subsection{Flexible Gas Sensors Substrates}

The design of the gas sensor substrate is shown in Fig. 1. It was designed based on the commercially available alumina substrates CC2 (BVT, Czech Republic), in which the geometry of the electrodes was set at the level that enables higher sensor sensitivity. The $\mathrm{CC} 2$ substrates (or similar) are widely used in the sensor society. A gas-sensitive layer was deposited on both substrates to allow comparison between the alumina and Kapton material. The shape of the electrodes enabled us to obtain a signal from the measuring electrode and the reference electrode at the same time. The electrode building process consists of three stages. First, a conductive layer is printed on a flexible substrate. For this stage, the aerosol jet printing technique was used with nanosilver ink from the UT Dots company. According to the manufacturer, the UTD AgTE ink based on the nanosilver particles is suitable for flexible substrates and after the sintering process, only silver material should be left in the layer. Because the sintering process is simply heating the ink to the temperature

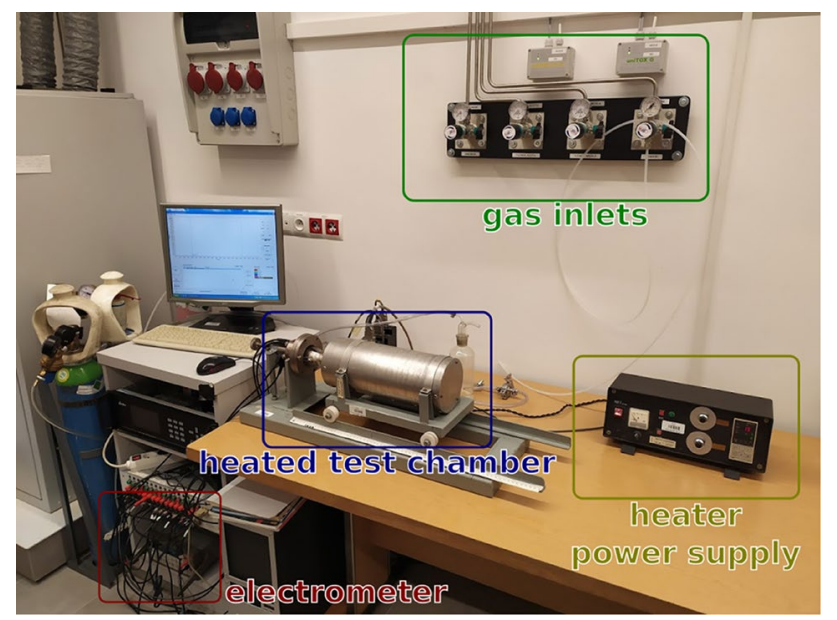

Fig. 3 The setup for gas-sensing characteristics measurements about $250{ }^{\circ} \mathrm{C}$, it is possible for some residuals to be left in the layer, e.g. from surfactants or solvents. After the conductive layer is built the functional layer is deposited on the sensor; this is the last manufacturing step. The electrode lines were $40 \mu \mathrm{m}$ wide and $2 \mu \mathrm{m}$ thick. The Kapton foil $74 \mu \mathrm{m}$ thick was used as a substrate material. This design of the sensor allows us to easily apply various gas-sensitive layers, such as metal oxides (schematically presented as blue boxes in Fig. 1).

Printed electrodes exhibit a slight non-linearity at the paths ends visible in Fig. 2, resulting from the limitations of aerosol printing deposition. The lines are homogeneous and parallel. Both the edges and the corners of the contact pads were printed correctly.

\subsection{Gas-Sensitive Layer}

The gas-sensitive layer was based on the copper oxide $(\mathrm{CuO})$, which was previously confirmed to be a good gassensitive material in various measurement methods [40-44]. The $\mathrm{CuO}$ thin films were deposited by the magnetron sputtering system with a glancing angle deposition technique (GLAD). The base vacuum pressure and deposition vacuum pressures were $1 \times 10^{-6} \mathrm{mbar}$ and $3 \times 10^{-3} \mathrm{mbar}$, respectively. The target to substrate distance was approximately $60 \mathrm{~mm}$ and the deposition temperature was $100{ }^{\circ} \mathrm{C}$. The sputtering was conducted in a pure oxygen atmosphere. In this case, a metallic target was firstly presputtered to remove any contamination in pure Ar for $10 \mathrm{~min}$ at $100 \mathrm{~W}$, then the pure $\mathrm{O}_{2}$ was introduced to the chamber; the power, temperature, oxygen flow was fixed at $50 \mathrm{~W}, 100{ }^{\circ} \mathrm{C}$ and $20 \mathrm{sccm}$.

\subsection{Gas-Sensing Measurements}

The developed sensor presented in Fig. $2 b$ was placed in the quartz-tube oven and the target gas at various concentrations was introduced. An electrometer (34401A HP) was used to record the electrical resistance changes. The various concentration levels were obtained by utilization of mass flow controllers 1179B (MKS Instruments, USA) and acetone canisters with $5 \mathrm{ppm}$ of acetone (Air Products, UK). The gas-sensing measurement system was previously described in detail [45]. The gas-sensing measurements were performed at various temperatures and $50 \%$ relative

Fig. 4 Representation of bending tests: linear bending in sensor long axis [in resting state (a) and compressed state (b)], rotation in sensor long axis [in resting state $(\mathbf{c})$ and rotated $(\mathbf{d})]$

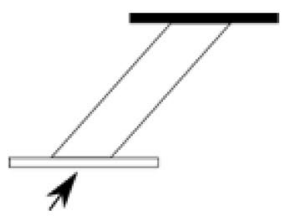

(a)

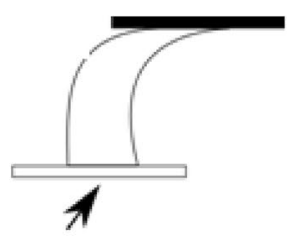

(b)

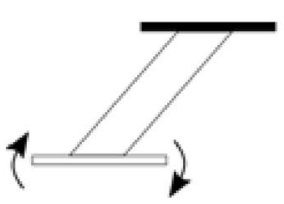

(c)

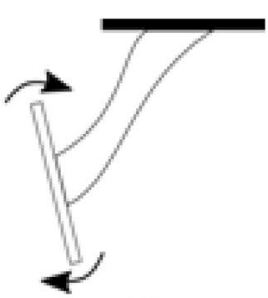

(d) 


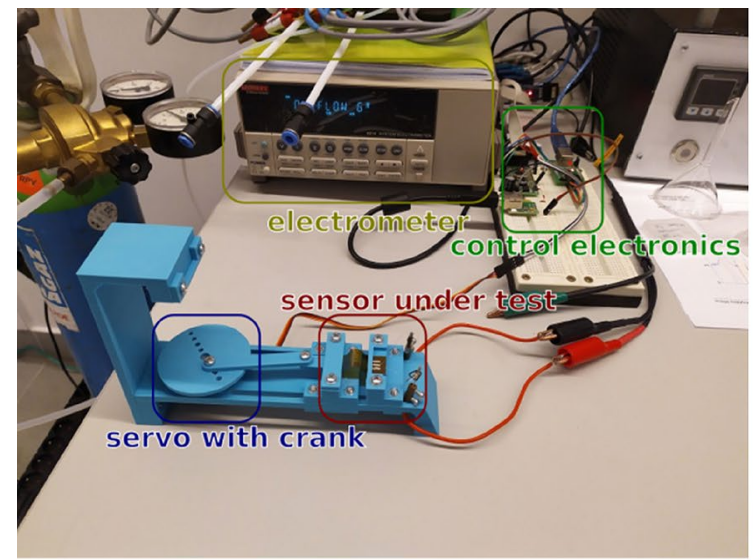

(a)

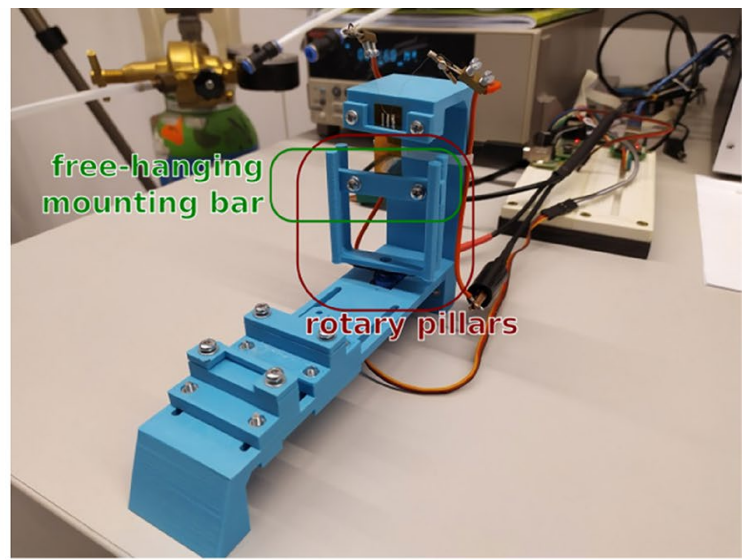

(b)

Fig. 5 Testbench for sensor durability and stability tests under banding: a configuration for linear bending in sensor long axis, b configuration for rotation in sensor long axis

humidity (RH) level. Figure 3 shows the measurement system. The gas sensor response $(\mathrm{S})$ was defined as resistance ratio $S=\left(R_{\text {gas }}-R_{\text {air }}\right) / R_{\text {air }}$, where $R_{\text {gas }}$ and $R_{\text {air }}$ are electrical resistances in gas and air, respectively.

\subsection{Mechanical Tests}

The mechanical stability tests were performed to verify the mechanical durability and possible distortions that may occur during the resistance measurements, which in turn may lead to errors of gas concentration measurement. A synthesized test procedure was developed, followed by the design of a testbench for automated testing. The flexible sensors can be bent in many degrees of freedom; the tests therefore should be limited to a set of well-defined bending directions. Let us denote the length of the substrate as the $\mathrm{X}$ direction and the width as Y. The fundamental deformations that can be introduced are (1) linear contraction in $\mathrm{X}$, (2) linear contraction in $\mathrm{Y}$, (3) axial twist in $\mathrm{X}$, (4) axial twist in Y. Because the sensor is significantly larger in the $\mathrm{X}$ direction than in $\mathrm{Y}$ and that the length of $Y$ is substantially small, the deformations introduced in $\mathrm{X}$ will be of greatly smaller magnitude. Thus the most impactful would be the linear (Fig. 4a, b) and axial deformation (Fig. 4c, d) in the X-axis. These assumptions were taken as the basis for designing a testbench for automated mechanical testing. The testbench was designed as a 3D model and manufactured using common FDM 3D printing in ABS material.

The testbench consists of a servomotor, with one of two adapters mounted on its axle-one for linear bending (Fig. 5a) and one for axial rotation (Fig. 5b). Iin the axial configuration the base of the sensor is mounted in a stationary clamp at the top of the device, while the tip is

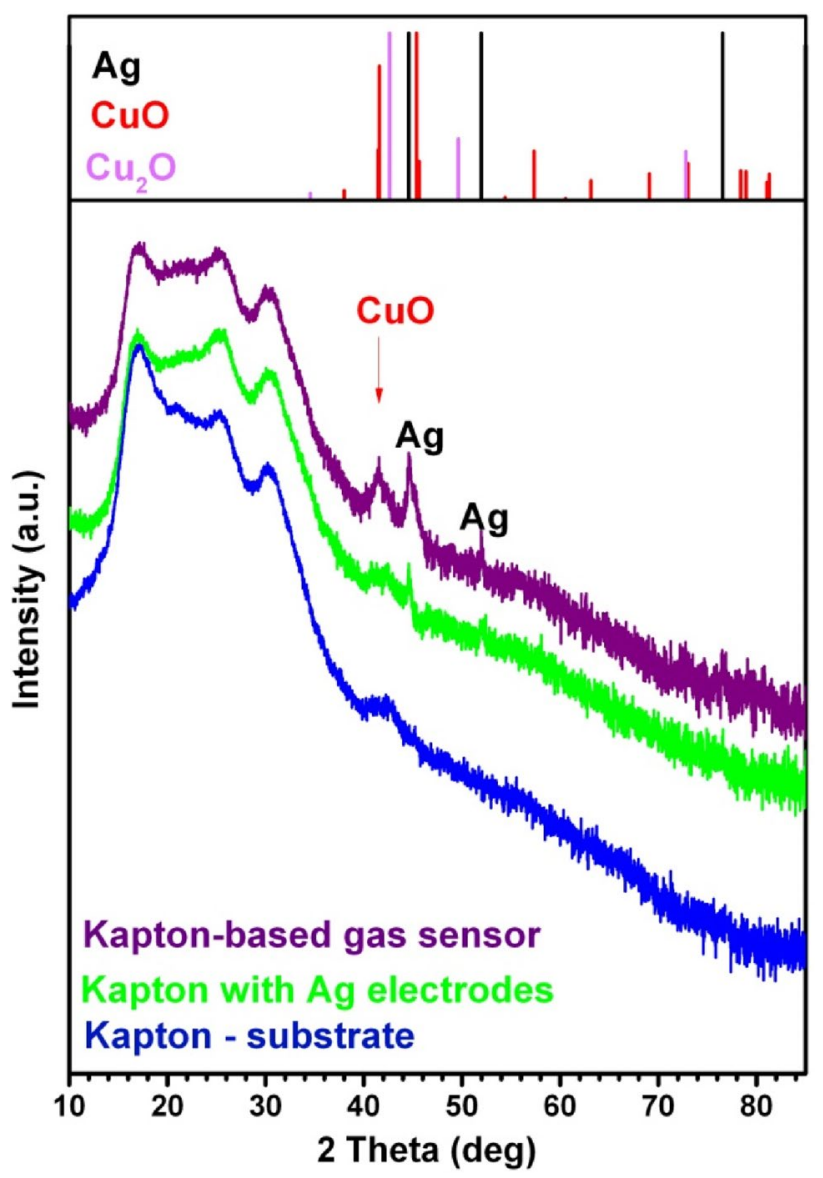

Fig. 6 XRD patterns of Kapton-based $\mathrm{CuO}$ thin film gas sensor 


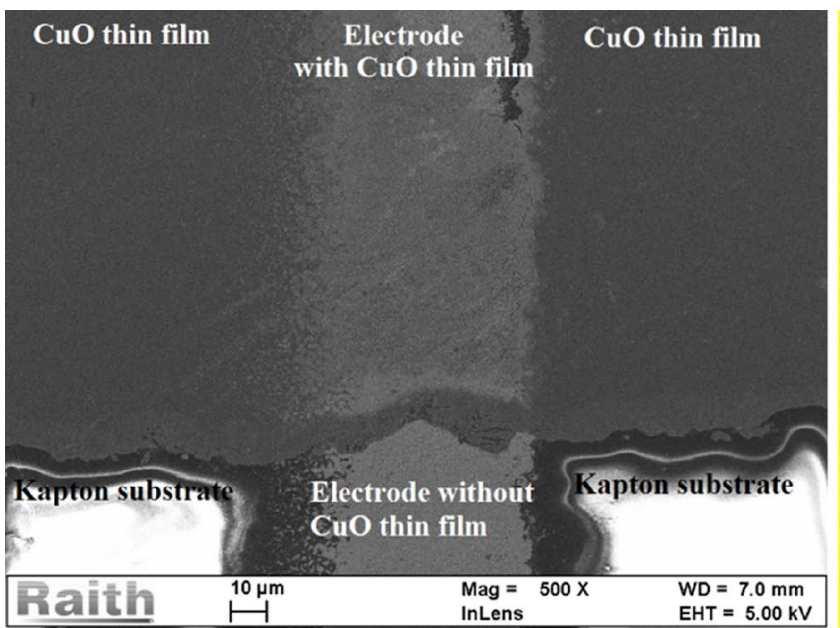

(a)

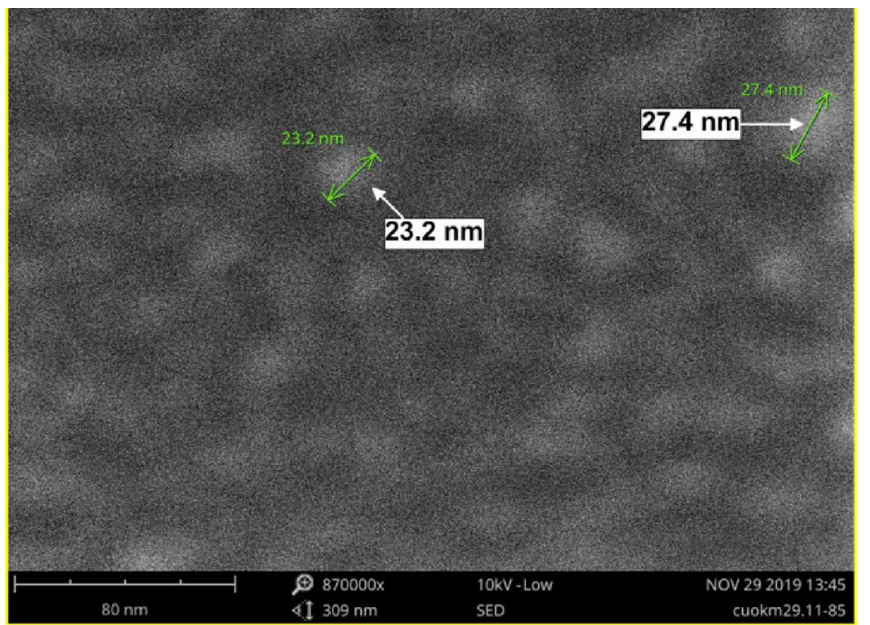

(b)

Fig. 7 SEM images of the fabricated sensors: a general view, b zoom $(\times 200000)$ of the $\mathrm{CuO}$ thin film deposited on the Kapton foil

fitted with a bar clamp and dangles loosely between rotating pillars. When the servo rotates the pillars by a certain angle, the sensor is also rotated. This rather unusual construction is necessary since during rotation the sensor is shortened in longitude. When the testbench is set up to test linear contraction, the servo adapter is swapped to a crank mechanism. The crank pushes a sliding clamp, clamping one end of the sensor, while the other end is in a stationary clamp. In both modes of operation, the sensor contacts are near the static clamps which allow for easy connection to an electrometer to measure resistance. The angle of the servomotor is controlled by a microcontroller with a USB serial interface, through which the setpoint angle is transmitted, the resistance of the gas-sensitive layer was measured by the electrometer (6514E, Keithley).

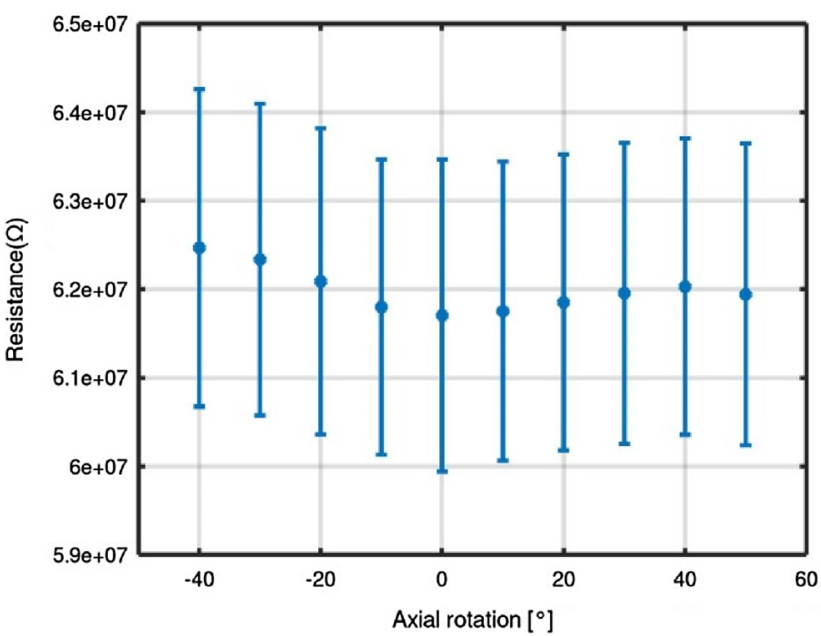

(a)

\section{Results and Discussion}

\subsection{Characterization}

In order to determine the sample phase composition, we used Panalytical Empyrean X-ray diffractometer with Co $\mathrm{K} \alpha$ radiation in grazing incidence configuration of $1^{\circ}$. Figure 6 shows the Grazing Incidence X-ray Diffraction (GIXD) patterns of Kapton-based $\mathrm{CuO}$ gas sensor as well as reference samples: silver contacts on polyimide Kapton substrate and polyimide Kapton substrate. Diffraction patterns for all three samples show the characteristic amorphous envelope and peaks due to some degree of crystallinity of the polyimide substrate [46] in the range of $2 \theta$

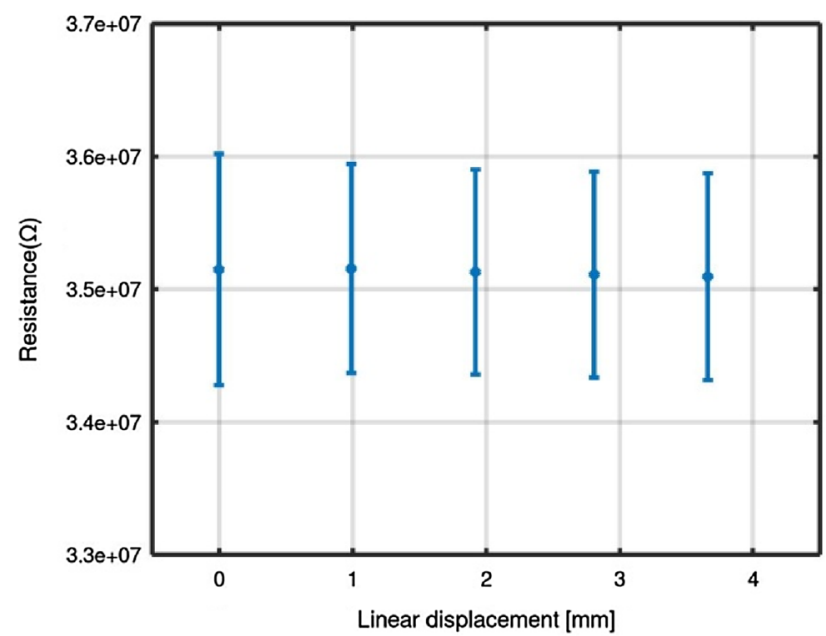

(b)

Fig. 8 Resistance changes during the mechanical tests: a axial rotation tests, $\mathbf{b}$ linear compression tests 


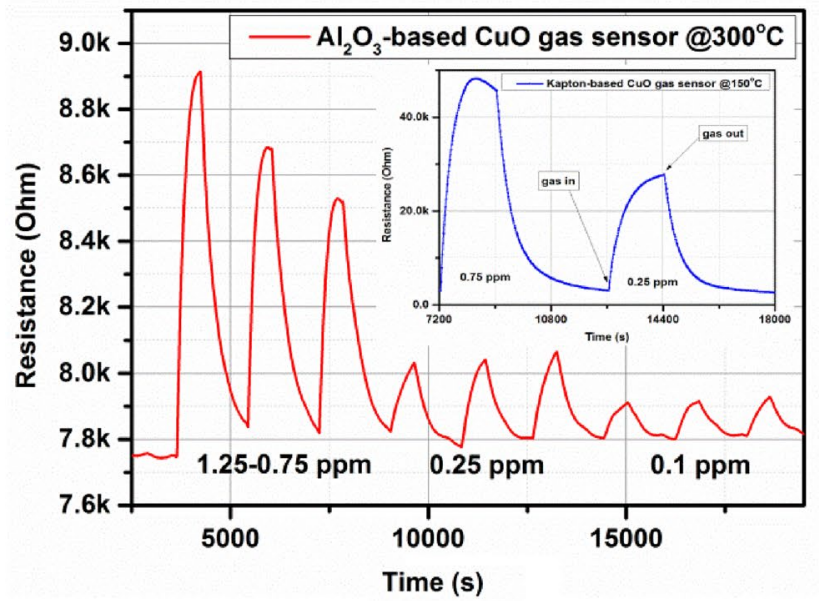

(a)

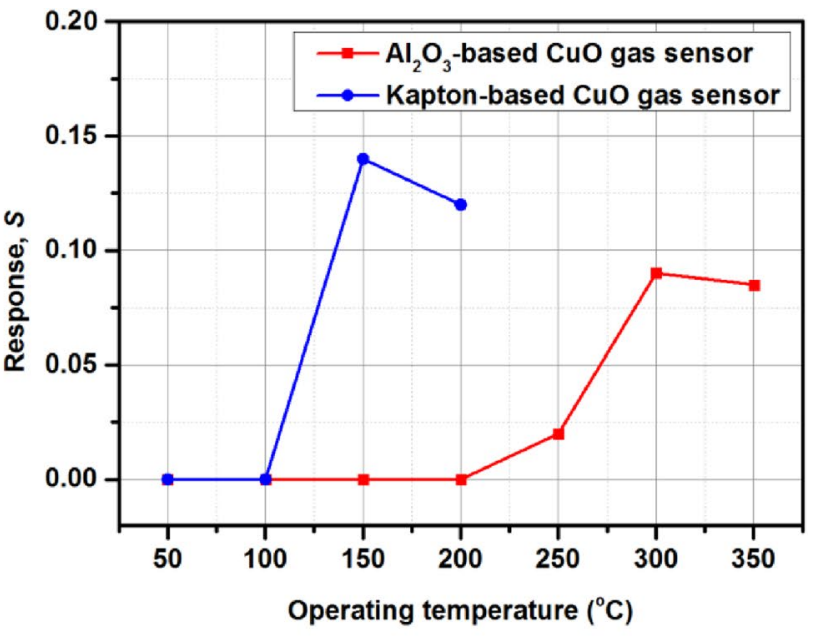

(b)

Fig. 9 Gas-sensing characteristics of Kapton-based and alumina-based $\mathrm{CuO}$ gas sensor obtained under exposure to acetone: a resistance changes measured in the $1.25-0.1 \mathrm{ppm}$ range, $\mathbf{b}$ response versus operating temperature under exposure to $0.75 \mathrm{ppm}$ of acetone $(50 \% \mathrm{RH})$

of $15^{\circ}-35^{\circ}$. The obtained pattern shows that the sensor is mostly amorphous material with one weak diffraction peak at $41.5^{\circ}$, which may indicate the presence of $\mathrm{CuO}$ phase and is convolution of $\mathrm{CuO}(-111)$ and (002) crystal planes [47]. In addition, there is no evidence of diffraction peaks for any other copper oxides phases. Low intensity GIXD peaks observed at $51.8^{\circ}$ and $51.8^{\circ}$, correspond to $\mathrm{Ag}$, which was used to make sensor electric contacts. Due to the low-intensity of diffraction peaks logarithmic scale was used to show the intensity curves along the y-axis. The
XRD patterns for alumina-based $\mathrm{CuO}$ gas sensors were previously presented and discussed in [40-44].

The morphology of thin films was examined by Scanning Electron Microscopy ZEISS Gemini SEM (5 kV, WD $7.0 \mathrm{~mm}$ ). SEM images are presented in Fig. 7. Figure 7a shows the general view of the sensor, where Kapton substrate uncovered and covered by $\mathrm{CuO}$ thin film is presented. The zoom $(\times 200,000)$ of the $\mathrm{CuO}$ thin film is presented in Fig. $7 \mathrm{~b}$.

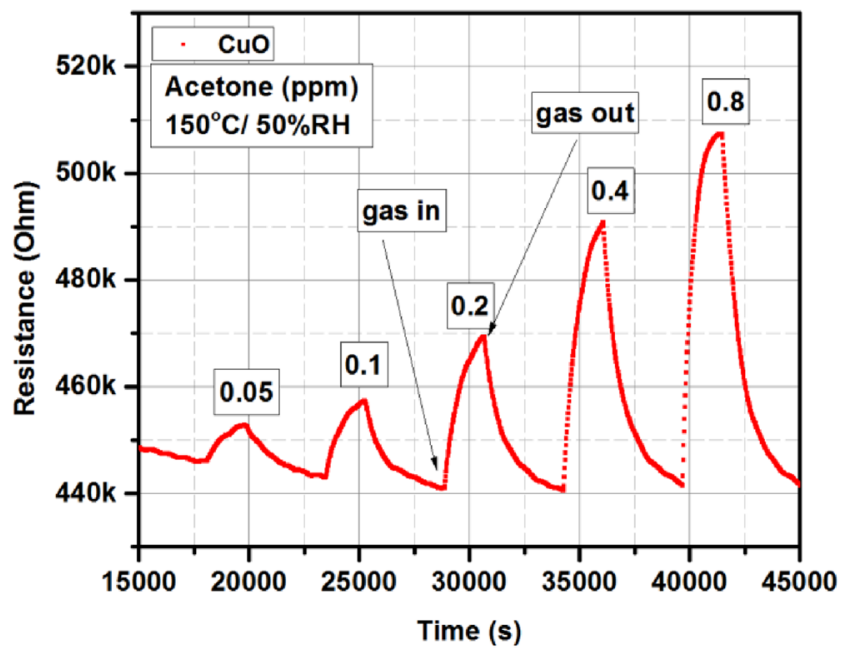

(a)

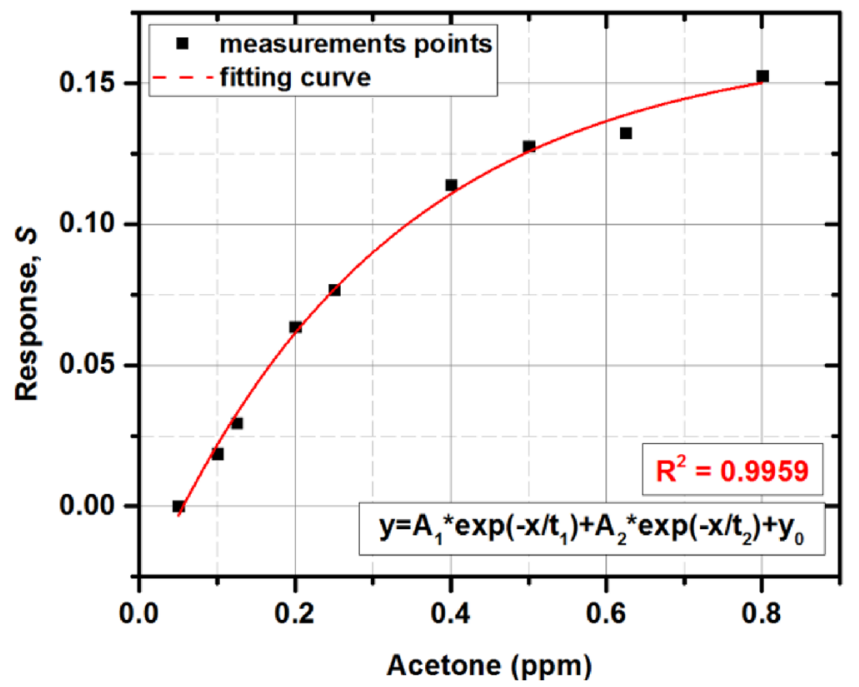

(b)

Fig. 10 Gas-sensing characteristics for Kapton-based $\mathrm{CuO}$ gas sensor: a the resistance changes, $\mathbf{b}$ the calibration curve of the $\mathrm{CuO}-$ based sensor in the $0.05-0.8 \mathrm{ppm}$ acetone range 


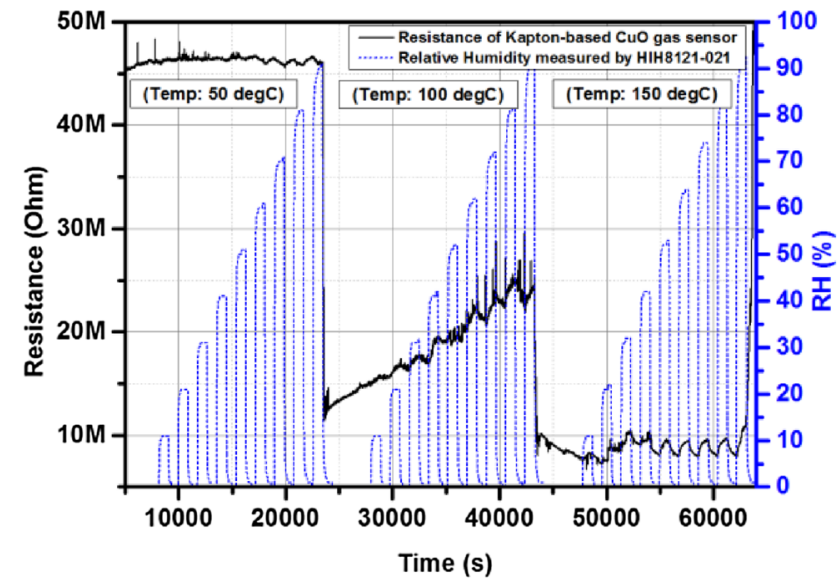

(a)

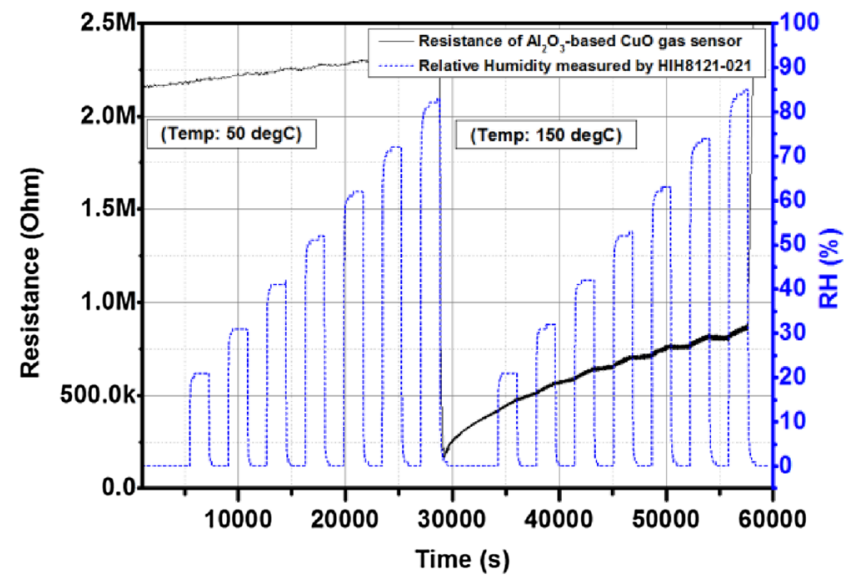

(b)

Fig. 11 Resistance changes measured at various relative humidity concentrations: a for Kapton-based $\mathrm{CuO}$ sensor at $50{ }^{\circ} \mathrm{C} / 100{ }^{\circ} \mathrm{C} / 150{ }^{\circ} \mathrm{C}, \mathbf{b}$ for alumina-based $\mathrm{CuO}$ sensor at $50{ }^{\circ} \mathrm{C}$ and $150{ }^{\circ} \mathrm{C}$

\subsection{Mechanical Results}

The measurement procedure is controlled by a Python program running on a PC. The PC has serial interfaces to control the servo angle and to trigger resistance measurements on the electrometer. The procedure is simple and involves changing the rotation angle or linear distance in equal steps and triggering a resistance measurement after each step. The initial series of axial rotation tests and linear compression tests are shown in Fig. 8a, b, respectively. In the case of axial tests, the sensor was bent both clockwise and counterclockwise in $10^{\circ}$ steps between $-50^{\circ}$ and $+50^{\circ}$. In the case of linear tests, the sensor was compressed from the resting (flat) position up to $3.6 \mathrm{~mm}$ compression and back in $0.9 \mathrm{~mm}$ steps. The graph shows little change in the sensor resistance when exposed go bending. In the case of linear deformation, the average resistance throughout all tests was $35.24 \mathrm{M} \Omega$ with a standard deviation of $735.8 \mathrm{k} \Omega$. In the case of axial deformation, the average resistance was $61.98 \mathrm{M} \Omega$ with a standard deviation of $1.72 \mathrm{M} \Omega$. However, it has to be underlined that such measurements were carried out at room temperature $\left(\sim 23^{\circ} \mathrm{C}\right)$ and relative humidity around $\sim 35 \%$.

\subsection{Gas-Sensing Characteristics}

The fabricated sensors were tested in the various temperature ranges dependent on the gas sensor substrates. The sensors were tested in the range of $50-200{ }^{\circ} \mathrm{C}$ for Kapton-based $\mathrm{CuO}$, since over $200{ }^{\circ} \mathrm{C}$ the Kapton foil with electrodes and thin-film lost their stability, and in the range of $50-350{ }^{\circ} \mathrm{C}$ for alumina-based. The highest responses were obtained at $150{ }^{\circ} \mathrm{C}$ and $300{ }^{\circ} \mathrm{C}$ for Kapton-based and alumina-based substrates, respectively. Figure 9 shows the gas-sensing characteristics measured under exposure to acetone in the
0.1-1.25 ppm range. The resistance changes are presented in Fig. 9a and sensitivity vs. operating temperature in Fig. 9b. As can be observed in Fig. 9b, the higher responses have been obtained for Kapton-based gas sensors, which is mostly related to different growth of the gas-sensitive layer on the Kapton foil in comparison with alumina substrate. The different growth impacts to higher surface to volume ratio. Moreover, the main goal was to reduce the operating temperature to the minimum, which will reduce the power consumption in the gas detectors.

Our main goal was to develop sensors able to detect acetone in the 'healthy;' and 'diabetic' range, which is $0.2-0.8 \mathrm{ppm}$ and over $2 \mathrm{ppm}$, respectively. The resistance changes of the $\mathrm{CuO}$-based Kapton sensor under exposure to acetone in the $0.05-0.8 \mathrm{ppm}$ range are presented in Fig. 10a. As can be noticed, sensors exhibited limit of detection as low as $0.05 \mathrm{ppm}$, and good response is obtained in the $0.05-0.8 \mathrm{ppm}$ acetone range. The calibration curve for the sensor is presented in Fig. 10b. Moreover, the exhaled breath consists of highly concentrated humidity. We therefore measured gas sensors response under exposure to various humidity concentrations (Fig. 11). As shown in Fig. 11, the Kapton-based $\mathrm{CuO}$ gas sensors are slightly sensitive to humidity changes in the $50-150{ }^{\circ} \mathrm{C}$ temperature range. The alumina-based $\mathrm{CuO}$ gas sensors are less sensitive to humidity in the same range; however, these sensors are not sensitive to acetone below $250{ }^{\circ} \mathrm{C}$ (Fig. 9b). While these developed sensors could be used with success for the exhaled acetone detection, the relative humidity level needs to be measured at the same time, and the final response has to be corrected for it.

Exhaled acetone is considered to be a biomarker of diabetes, which is why gas sensors with a limit of detection in the sub-ppm range are of high interest. We must emphasize 
that there are so far no commercially available sensors for acetone detection in the 'diabetic' and 'healthy' regimes. Additionally, sensors with flexible construction can be used to develop other novel sensing devices, which can be easily integrated into electronic devices or clothes.

\section{Conclusions}

We describe the design, preparation, and experimental results for the gas sensors deposited on an elastic substrate. Our results demonstrate that electrodes aerosol jet printed on flexible substrates are suitable for the fabrication of gas sensors with metal oxides based gas-sensitivity layers. Kapton-based $\mathrm{CuO}$ gas sensor exhibited a sub-ppm detection limit for acetone at $150{ }^{\circ} \mathrm{C}$ temperature. Sensors were tested under exposure to other compounds, such as hydrogen and propane; however, the responses obtained for those gases were below $3 \%$. Future work will focus on the application for portable devices for diabetes diagnostics. The design of multi-sensors matrix on the elastic substrate is a key problem for the construction of such devices. One of the designs described in this paper is currently patent pending [23]. The mechanical test confirmed a possibility of utilizing such sensors in a portable application.

Author Contributions AR and MS: conceptualization, AR, WA, JK, KS, MS: methodology, WA: software, AR, WA, JK, KS, MS, KM: validation, AR, WA, JK, KS, MS, KM: investigation, AR, WA, JK, KS, MS, KM: writing — original draft preparation, AR, WA, JK, KS, MS, KM: writing - review and editing, AR, WA, JK, KS, MS: visualization, AR, KM, MS: supervision, AR and MS project administration.

Funding This research is part of the "Functional heterophase materials for structural electronics" project carried out within the First TEAM/2016-1/7 programme of the Foundation for Polish Science cofinanced by the European Union under the European Regional Development Fund and partially funded by the National Science Centre, Poland 2017/26/D/ST7/00355.

\section{Compliance with Ethical Standards}

Conflicts of interest The authors declare no conflict of interest.

Open Access This article is licensed under a Creative Commons Attribution 4.0 International License, which permits use, sharing, adaptation, distribution and reproduction in any medium or format, as long as you give appropriate credit to the original author(s) and the source, provide a link to the Creative Commons licence, and indicate if changes were made. The images or other third party material in this article are included in the article's Creative Commons licence, unless indicated otherwise in a credit line to the material. If material is not included in the article's Creative Commons licence and your intended use is not permitted by statutory regulation or exceeds the permitted use, you will need to obtain permission directly from the copyright holder. To view a copy of this licence, visit http://creativecommons.org/licenses/by/4.0/.

\section{References}

1. Tille, T.: Automotive suitability of air quality gas sensors. Sens Actuators B 170, 40-44 (2012)

2. Mohankumar, P., Ajayan, J., Yasodharan, R., Devendran, P., Sambasivam, R.: A review of micromachined sensors for automotive applications. Measurement 140, 305-322 (2019)

3. Rydosz, A.: Sensors for enhanced detection of acetone as a potential tool for noninvasive diabetes monitoring. Sensors 18, 2298 (2018)

4. Righettoni, M., Schmid, A., Amann, A., Pratsinis, S.E.: Correlations between blood glucose and breath components from portable gas sensors and PTR-TOF-MS. Breath Res. 7, 037110 (2013)

5. Saidi, T., Zaim, O., Moufid, M., Bari, N.E., Ionescu, R., Bouchikhi, B.: Exhaled breath analysis using electronic nose and gas chromatography-mass spectrometry for non-invasive diagnosis of chronic kidney disease, diabetes mellitus and healthy subjects. Sens. Actuators B 257, 178-188 (2018)

6. Kita, J., Schubert, F., Retting, F., Engelbrecht, A., Gross, A., Moos, R.: Ceramic alumina substrates for high-temperature gas sensors-implications for applicability. Proc. Eng. 87, 1505-1508 (2017)

7. Bartsch, H., Stoepel, D., Mueller, J., Rydosz, A.: Printed heater elements for smart sensor packages in LTCC. In: 2017 21st European Microelectronics and Packaging Conference (EMPC) \& Exhibition, 10-13 Sept. 2017. IEEE Xplore. https://doi. org/10.23919/empc.2017.8346841

8. Rydosz, A., Maziarz, W., Pisarkiewicz, T.: Formation a uniform temperature distribution in semiconductors resistance gas sensors in LTCC technology. Electr. Rev. 87, 24-252 (2011)

9. Rydosz, A., Szkudlarek, A., Ziabka, M., Domanski, K., Maziarz, W., Pisarkiewicz, T.: Performance of Si-doped $\mathrm{WO}_{3}$ thin films for acetone sensing prepared by glancing angle DC magnetron sputtering. IEEE Sens. J. 16, 1004-1012 (2016)

10. Ozdemir, S., Gole, J.L.: The potential of porous silicon gas sensors. Curr. Opin. Solid State Mater. Sci. 11, 92-100 (2007)

11. Dey, A.: Semiconductor metal oxide gas sensors: a review. Mater. Sci. Eng. B 229, 206-217 (2018)

12. Gao, X., Zhang, T.: An overview: facet-dependent metal oxide semiconductor gas sensors. Sens. Actuators B 277, 604-633 (2018)

13. Eranna, G.: Metal oxide nanostructures as gas sensing devices. CRC Press, Book (2011)

14. Korotcenkov, C., Cho, K.B.: Metal oxide composites in conductometric gas sensors: achievements and challenges. Sens. Actuators B 244, 182-210 (2017)

15. Jang, N.-S., Kim, M.S., Kim, S.-H., Lee, S.-K., Kim, J.-M.: Direct growth of titania nanotubes on plastic substrates and their application to flexible gas sensors. Sens. Actuators B 199, 361-368 (2014)

16. Vallejos, S., Gracia, I., Bravo, J., Figueras, E., Hubalek, J., Cane, C.: Detection of volatile organic compounds using flexible gas sensing devices based on tungsten oxide nanostrucutres functionalized with Au and Pt nanoparticles. Talanta 139, 27-34 (2015)

17. Kumar, L., Rawal, I., Kaur, A., Annapoorni, S.: Flexible room temperature ammonia sensor based on polyaniline. Sens. Actuators B 240, 408-416 (2017)

18. Hua, Ch., Shang, Y., Wang, Y., Xu, J., Zhang, Y., Li, X., Cao, A.: A flexible gas sensor based on single-walled carbon nanotube$\mathrm{Fe}_{2} \mathrm{O}_{3}$ composite film. Appl. Surf. Sci. 405, 405-411 (2017)

19. Sarfraz, J., Fogde, A., Ihalainen, P., Peltonen, J.: The performance of inkjet-printed copper acetate-based hydrogen sulfide gas sensor on a flexible plastic substrate-varying ink composition and print density. Appl. Surf. Sci. 445, 89-96 (2018) 
20. Wang, K., Wei, W., Lou, Z., Zhang, H., Wang, L.: 1D/2D heterostructure nanofiber flexible sensing device with efficient gas detectivity. Appl. Surf. Sci. 479, 209-215 (2019)

21. Zhou, X., Guo, W., Fu, J., Zhu, Y., Huang, Y., Peng, P.: Laser writing of $\mathrm{Cu} / \mathrm{Cu}_{\mathrm{x}} \mathrm{O}$ integrated structure on flexible substrate for humidity sensing. Appl. Surf. Sci. 494, 684-690 (2019)

22. Alrammouz, R., Podlecki, J., Abboud, P., Sorli, B., Habchi, R.: A review on flexible gas sensors: From materials to devices. Sens. Actuators A 284, 209-231 (2018)

23. Rydosz, A., Marszalek, K.: Portable device for detection of biomarkers in exhaled air and method of biomarker detection in exhaled air. EP18190345.1 (2018)

24. Asad, M., Sheikhi, M.H., Pourfath, M., Moradi, M.: High sensitive and selective flexible $\mathrm{H}_{2} \mathrm{~S}$ gas sensors based on $\mathrm{Cu}$ nanoparticle decorated SWCNTs. Sens. Actuators B 210, 1-8 (2015)

25. Li, S., Diao, Y., Yang, Z., He, J., Wang, J., Liu, C., Liu, F., Lu, H., Yan, X., Sun, P., Lu, G.: Enhanced room temperature gas sensor based on Au-loaded mesoporous $\operatorname{In}_{2} \mathrm{O}_{3}$ nanospheres@ polyaniline core-shell nanohybrid assembled on flexible PET substrate for $\mathrm{NH}_{3}$ detection. Sens. Actuators B 276, 526-533 (2018)

26. Kulkarni, S.B., Navale, Y.H., Navale, S.T., Stadler, F.J., Ramgir, N.S., Patil, V.B.: Hybrid polyaniline- $\mathrm{WO}_{3}$ flexible sensor: a room temperature competence towards $\mathrm{NH}_{3}$ gas. Sens. Actuators B 288, 279-288 (2019)

27. Zhang, D., Wu, Z., Zong, X.: Flexible and highly sensitive $\mathrm{H}_{2} \mathrm{~S}$ gas sensor based on in situ polymerized $\mathrm{SnO}_{2} / \mathrm{rGO} / \mathrm{PANI}$ ternary nanocomposite with application in halitosis diagnosis. Sens. Actuators B 289, 32-41 (2019)

28. Kuberský, P., Syrový, T., Hamácek, A., Nespurek, S., Stejskal, J.: Printed flexible gas sensors based on organic materials. Procedia Eng. 120, 614-617 (2015)

29. Uddin, A.I., Yaqoob, U., Phan, D.T., Chung, G.S.: A novel flexible acetylene gas sensor based on PI/PTFE-supported Ag-loaded vertical $\mathrm{ZnO}$ nanorods array. Sens. Actuators B 222, 536-543 (2016)

30. Lou, Z., Wang, L., Jiang, K., Shen, G.: Programmable threedimensional advanced materials based on nanostructures as building blocks for flexible sensors. Nano Today 26, 176-198 (2019)

31. Gardon, M., Monereo, O., Dosta, S., Vescio, G., Cirera, A., Guilemany, J.M.: New procedures for building-up the active layer of gas sensors on flexible polymers. Surf. Coat. Technol. 235, 848-852 (2013)

32. Vallejos, S., Gràciaa, I., Figueras, E., Sánchez, J., Mas, R., Beldarrain, O., Canéa, C.: Microfabrication of flexible gas sensing devices based on nanostructured semiconducting metal oxides. Sens. Actuators 219, 88-93 (2014)

33. Claramunt, S., Monereo, O., Boix, M., Leghriba, R., Prades, J.D., Cornet, A., Merino, P., Merino, C., Cirera, A.: Flexible gas sensor array with an embedded heater based on metal decorated carbon nanofibres. Sens. Actuators B 187, 401-406 (2013)

34. Liu, C., Tai, H., Zhang, P., Yuan, Z., Du, X., Xie, G., Jiang, Y.: A high-performance flexible gas sensor based on self-assembled
PANI- $\mathrm{CeO}_{2}$ nanocomposite thin film for trace-level $\mathrm{NH}_{3}$ detection at room temperature. Sens. Actuators B 261, 587-597 (2018)

35. Liu, B., Liu, X., Yuan, Z., Jiang, Y., Su, Y., Ma, J., Tai, H.: A flexible $\mathrm{NO}_{2}$ gas sensor based on polypyrrole/nitrogen-doped multiwall carbon nanotube operating at room temperature. Sens. Actuators B 295, 86-92 (2019)

36. Perillo, P.M., Rodríguez, D.F.: Low temperature trimethylamine flexible gas sensor based on $\mathrm{TiO}_{2}$ membrane nanotubes. J. Alloys Compd. 657, 765-769 (2016)

37. Acuautla, M., Bernardini, S., Gallais, L., Bendahan, M.: Direct laser patterning of a gas sensor on flexible substrate. Procedia Eng. 87, 899-902 (2014)

38. Chen, Q., Liu, D., Lin, L., Wu, J.: Bridging interdigitated electrodes by electrochemical-assisted deposition of graphene oxide for constructing flexible gas sensor. Sens. Actuators B 286, 591599 (2019)

39. Park, H.J., Kim, W.J., Lee, H.K., Lee, D.S., Shin, J.H., Jun, Y., Yun, Y.J.: Highly flexible, mechanically stable, and sensitive $\mathrm{NO}_{2}$ gas sensors based on reduced graphene oxide nanofibrous mesh fabric for flexible electronics. Sens. Actuators B 257, 846-852 (2018)

40. Rydosz, A., Szkudlarek, A.: Gas sensing performance of M-doped $\mathrm{CuO}$-based thin films working at different temperatures upon exposure to propane. Sensors 15, 20069-20085 (2015)

41. Rydosz, A.: Amorphous and nanocrystalline magnetron sputtered $\mathrm{CuO}$ thin films deposited on low temperature cofired ceramics substrates for gas sensor applications. IEEE Sens. J. 14, 1600 1607 (2014)

42. Rydosz, A.: The use of copper oxide thin films in gas-sensing applications coatings 8, 425 (2018)

43. Kollbek, K., Szkudlarek, A., Klejna, S., Rydosz, A.: Electronic sensitization of $\mathrm{CuO}$ thin films by $\mathrm{Cr}$-doping for enhanced gas sensor response at low detection limit. Mater. Res. Express 5, 126406 (2018)

44. Rydosz, A., Maziarz, W., Brudnik, A., Czapla, A., Zakrzewska, $\mathrm{K} . \mathrm{CuO}$ and $\mathrm{CuO} / \mathrm{TiO}_{2-\mathrm{y}}$ thin-film gas sensors of $\mathrm{H}_{2}$ and $\mathrm{NO}_{2}$. In: 2018 XV International Scientific Conference on Optoelectronic and Electronic Sensors (COE), Warsaw, Poland

45. Lyson-Sypien, B., Czapla, A., Lubecka, M., Gwizdz, P., Schneider, K., Zakrzewska, K., Michalow, K., Graule, T., Reszka, A., Rekas, M., Lacz, A., Radecka, M.: Nanopowders of chromium doped $\mathrm{TiO}_{2}$ for gas sensors. Sens. Actuators B 175, 163-172 (2012)

46. Cardoso, J., Gomez-Daza, O., Ixtilco, L., Nair, M.T.S., Nair, P.K.: Conductive copper sulfide thin films on polyimide foils. Semicond. Sci. Tech. 16, 123-127 (2001)

47. Garcia-Martinez, O., Rojas, R.M., Vila, E., Martin de Vidales, J.L.: Microstructural characterization of nanocrystals of $\mathrm{ZnO}$ and $\mathrm{CuO}$ obtained from basic salts. Solid State Ion. 63-65, 442-449 (1993)

Publisher's Note Springer Nature remains neutral with regard to jurisdictional claims in published maps and institutional affiliations. 